Check for updates

Cite this: RSC Adv., 2019, 9, 19596

Received 5th May 2019

Accepted 18th June 2019

DOI: $10.1039 / \mathrm{c} 9 \mathrm{ra03354h}$

rsc.li/rsc-advances

\section{Highly functionalized calix[4]arenes via multicomponent reactions: synthesis and recognition properties}

\author{
Reza Zadmard, (D) * Ali Akbarzadeh and Mohammad Reza Jalali
}

\begin{abstract}
Multicomponent reactions (MCRs) include several aspects of green chemistry principles, so it is obvious that chemists in different areas are increasingly interested in providing their product by multicomponent approaches. MCRs can be very useful in supramolecular chemistry, especially to produce novel supramolecular derivatives. Therefore, there are several reports of highly-functionalized calix[4]arene derivatives obtained by MCRs instead of conventional stepwise protocols during the last decade. In this paper, we have particularly focused on the exploitation of upper rim and lower rim substituted calix[4] arenes in multicomponent approaches as a facile and convenient synthetic strategy. The value of this method lies in its operational simplicity, mild reaction conditions and structural diversity of the products. Interestingly, in most cases the products afforded by this method offer unique features and applications which are highlighted in the following sections.
\end{abstract}

\section{Introduction}

Supramolecular chemistry deals with reversible noncovalent interactions between two or more molecules or ions. ${ }^{\mathbf{1} 2}$ It can also be described as chemistry beyond the molecule in view of the fact that simpler chemical species can create more complex structures such as supramolecular entities through the utilization of non-covalent interactions, such as electrostatics, hydrogen binding, van der Waals and donor-acceptor interactions. ${ }^{3,4}$ Both host-guest chemistry and self-assembly are main branches of supramolecular chemistry which are often distinguishable from each other by the size and shape of the species. Generally, the host is the larger molecule which can embrace another one via its binding sites whereas the guest is the smaller one embraced by the host. Where there is no significant difference between species in the size and shape, the non-covalent aggregating of two or more species is termed self-assembly. ${ }^{5}$ These types of interactions are the origin of many biological processes and can be used in the development of various synthetic enzymes, drugs and molecular receptors. ${ }^{6,7}$

Calix[4]arenes are basket like cyclic phenol formaldehyde tetramers which create a hollow cavity flanked by a hydrophobic upper rim (aromatic moiety) and a hydrophilic lower rim (hydroxyl groups). ${ }^{8-10}$ The possibility of divers functionalization at lower and/or upper rim as well as unique conformational properties have made calix[4]arenes

Department of Organic Chemistry, Chemistry and Chemical Engineering Research Center of Iran, P. O. Box 14335-186, Tehran, Iran. E-mail: zadmard@ccerci.ac.ir; Fax: +98 2144787785; Tel: +982144787719 versatile templates to design outstanding supramolecular structures with several binding sites in an array complementary to a potential guest. ${ }^{11-13}$ The molecular hosts based on calix[4]arene scaffold have been employed in many applications, ${ }^{\mathbf{1 4 , 1 5}}$ such as chemical sensing, ${ }^{\mathbf{1 6 - 1 8}} \mathrm{drug}$ and gen delivery, ${ }^{19-22}$ enzyme mimicking, ${ }^{\mathbf{2 3 , 2 4}}$ stationary phase,$^{25-27}$ extractants, ${ }^{28,29}$ enzyme inhibitors, ${ }^{30-32}$ catalysts ${ }^{33-35}$ and etc.

Multicomponent reaction (MCR) is defined as a chemical process between more than two substances which afford a more complicated product through formation of multiple bonds in a single step. ${ }^{36-38}$ In the point of view of green organic synthesis, MCRs possess many advantages over conventional approaches such as high atom economy, simple operation, affording highly functionalized molecules in lower reaction and purification steps, saving energy and resources. ${ }^{39,40}$ Nowadays, owing to structural diversity of the multicomponent reaction products, many industrial and academic researchers are interested in developing new biologically active compounds through MCR protocols. ${ }^{41,42} \mathrm{~A}$ survey of the literature reveals that increasing efforts have been made to develop novel calix[4] arene derivatives through MCRs during the last decade. Also, there are several reports on using calix[4] arene derivatives as organocatalysts in MCRs which are not within the scope of this review. ${ }^{\mathbf{4 3 - 4 5}}$ Actually, the purpose of this review is to summarize all of the works conducted using MCR protocols to synthesize novel multifunctionalized calix[4]arene derivatives. As will be shown in further sections, most of the products have special recognition properties. 


\section{Lower rim functionalized calix[4]arene derivatives}

As the chemistry of calixarenes is well known nowadays, there are efficient procedures to functionalize both the lower and the upper rim with various functional groups. ${ }^{46}$ In most cases, functional groups have been attached to the lower rim via ether linkages. By the introduction of proper bulky groups such as propyl at the lower rim the interconversion among four possible stereoisomers (cone, partial cone, 1,3-alternate and 1,2-alternate) can be prevented. ${ }^{47}$ This way, calix[4]arene structure can be locked in its cone conformation. Compound 3 as a 1,3-dialdehyde $p$-tert-butylcalix[4]arene derivative have been used in several MCRs. In order to achieve compound 3 in excellent yields, $p$-tert-butylcalix[4]arene 1 was refluxed with 5 equivalent of 1,3-dibromopropane in the presence of $\mathrm{K}_{2} \mathrm{CO}_{3}$ in dry acetonitrile for 48-96 $\mathrm{h}$. Then in a similar manner, obtaining 1,3bis(bromopropane)-p-tert-butylcalix[4]arene 2 was refluxed in anhydrous acetonitrile with 4 equivalent of $p$-hydroxybenzaldehyde in the presence of $\mathrm{K}_{2} \mathrm{CO}_{3}$ under a nitrogen atmosphere (Scheme 1). ${ }^{48}$

The Ugi-4CR is an isocyanide-based multicomponent reaction between an isocyanide, a carbonyl compound, a primary amine, and a carboxylic acid that affords $\alpha$-acylamido amide derivatives as peptide-like structures. The use of compound 3 in Ugi-4-component reaction (Ugi-4CR) to produce a series of calix [4]arene peptoids was firstly described by Varma and coworkers (Scheme 2).

Additionally, the reaction of dialdehyde 3 as the carbonyl compound with some of chiral N-protected alpha-amino acids such as Boc-glycine, Boc---alanine, and Boc---tryptophan has afforded the products which have the potential to establish one more peptoide bond at the lower rim (Scheme 3). However, the synthesis of similar calix[4]arene derivatives is otherwise very difficult and involves multiple steps. The products obtained by this method have several non-bonding electron pairs which make them able to conduct intermolecular interactions with suitable guests. Among these new calix[4]arene derivatives, compound 3a has shown a significant change in colour and UV absorption toward the $\mathrm{Cu}^{2+}$ cation in $\mathrm{CH}_{3} \mathrm{CN}$, even in the presence of other metal cations (Fig. 1).

The UV-Vis titration revealed an isosbestic point at $296 \mathrm{~nm}$ in the range of $0-4$ equivalent of $\mathrm{Cu}^{2+}$. By Increasing of $\mathrm{Cu}^{2+}$ concentration between 4-30 equivalent, a new peak began to appear at $274 \mathrm{~nm}$, as well as the complex band at $474 \mathrm{~nm}$ continuously increased and the colour of the solution gradually

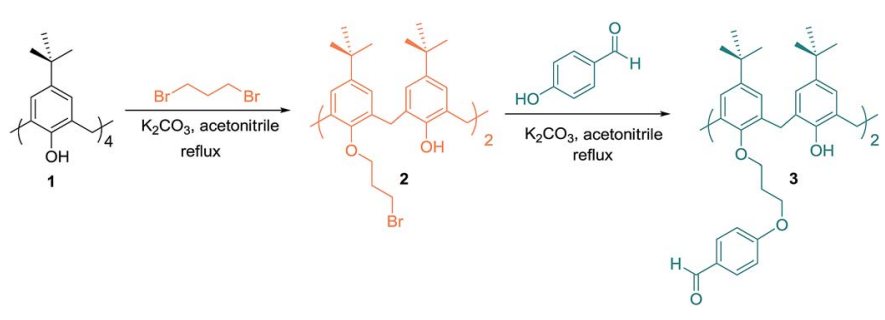

Scheme 1 Synthesis of calixarene dialdehyde 3 turned from colourless to orange. Addition of more $\mathrm{Cu}^{2+} \mathrm{did}$ not lead to any further significant change in the absorbance spectra. The UV-Vis spectral changes of 3a were also observed in the competitive presence of other metal cations which imply that $\mathrm{Cu}^{2+}: 3 a$ complex is unaffected even in the presence of 40 equivalent of many other cations ${ }^{49}$

Additionally, Varma and coworkers have successfully used compound 3 to synthesize of dihydropyrimidine derivatives via well-known Biginelli-3-Component Reaction (Biginelli-3CR) in good to excellent yields. An extended library of dihydropyrimidine derivatives with important biological properties has been available by Biginelli-3CR which was firstly reported in 1893 by the Italian Chemist Pietro Biginelli. ${ }^{50}$ The reaction of compound 3 with ethyl acetoacetate (or acetyl acetone) and urea (or thiourea) was carried out in acetonitrile as solvent, using phenylboronic acid as a non-toxic and cheap catalyst (Scheme 4). In some cases, significant inter-molecular interactions were revealed by the investigation of aggregation behaviour in nonpolar solvents like chloroform. ${ }^{51}$

Another reaction was conducted by Zadmard et al. between compound 3 with Meldrum's acid, isocyanides and primary amines in dry $\mathrm{CH}_{2} \mathrm{Cl}_{2}$ to produce various calix[4]arene based hexamides in a convenient manner and good yields (Scheme 5).

The presence of amide groups leads to increased hydrogen bonding affinity of the molecule and makes it a suitable host to embrace a guest such as a protein. Moreover, these amide groups can improve the water solubility of hydrophobic calix[4] arene moiety. Fluorescence quenching study revealed that among all the derivatives, compound $\mathbf{3 e}$ has the highest binding affinity toward $\beta$-lactoglobulin (BLG) protein (Scheme 6). Additionally, three-dimensional (3D) fluorescence spectroscopy investigations proved a complex formation mechanism for the interactions between calix[4]arene hexamides and BLG which did not cause considerable conformational changes in the protein structure (Fig. 2).

3D fluorescence spectroscopy is a suitable method to gather detailed information about the conformational changes in proteins. ${ }^{52}$ Thus, the 3D fluorescence spectra of BLG (A) and 3e : BLG complex (B) are shown in Fig. 2 and the corresponding characteristic parameters are listed in Table 1. In this figure, peaks a and b respectively were assigned as the first-order Rayleigh scattering peak $\left(\lambda_{\mathrm{ex}}=\lambda_{\mathrm{em}}\right)$ and second-order Rayleigh scattering peak $\left(2 \lambda_{\mathrm{ex}}=\lambda_{\mathrm{em}}\right)$. Moreover, peak 1 refers to tryptophan and tyrosine residues in BLG, and peak 2 is the spectral response of the polypeptide backbone structure in BLG protein. Rayleigh scattering peaks a and $\mathrm{b}$ were intensified by the addition of compound $3 \mathbf{e}$. This was probably due to formation of 3e : BLG complex which increases the diameter of BLG. Furthermore, the intensity of peaks 1 and 2 significantly decreased without any variation in maximum emission and excitation wavelengths. The obtained results disclosed that any change in microenvironment of the tryptophan and tyrosine did not occur. ${ }^{53}$

Also, the binding affinity of compound 3f toward some proteins has been investigated in a similar study (Scheme 7). Surprisingly, it was found that the binding affinity of $\mathbf{3} \mathbf{f}$ toward lysozyme (Lys) is significantly higher than the others (Table 2). 


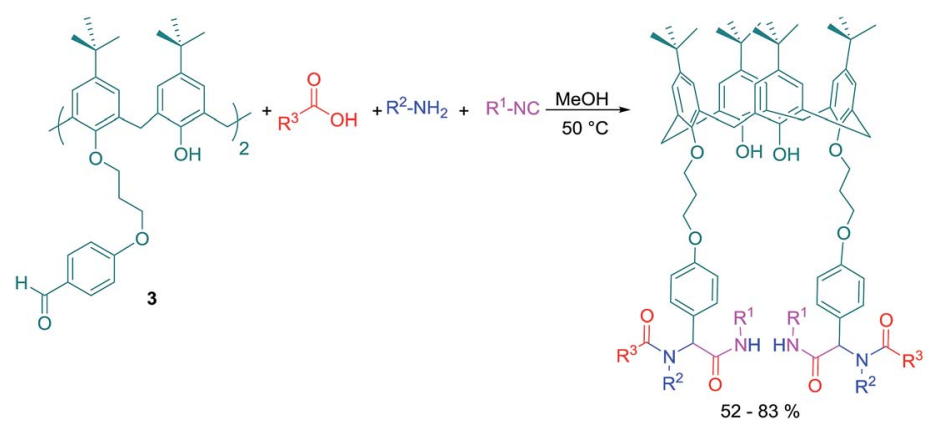

Scheme 2 Ugi-4-component reaction of calixarene dialdehyde 3 .

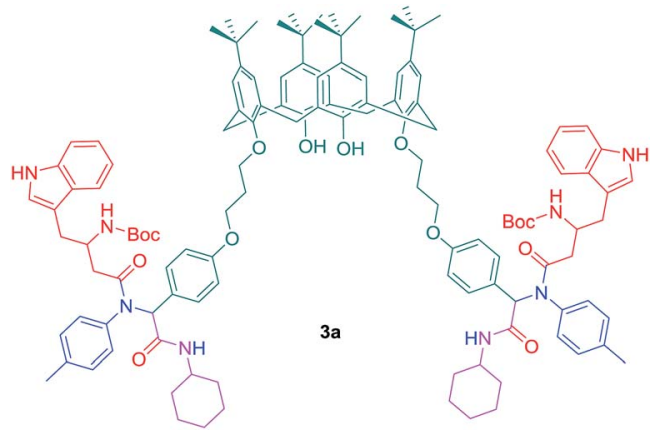

Scheme 3 Compound $3 \mathrm{a}$ as a selective molecular host for $\mathrm{Cu}^{2+}$ cation.

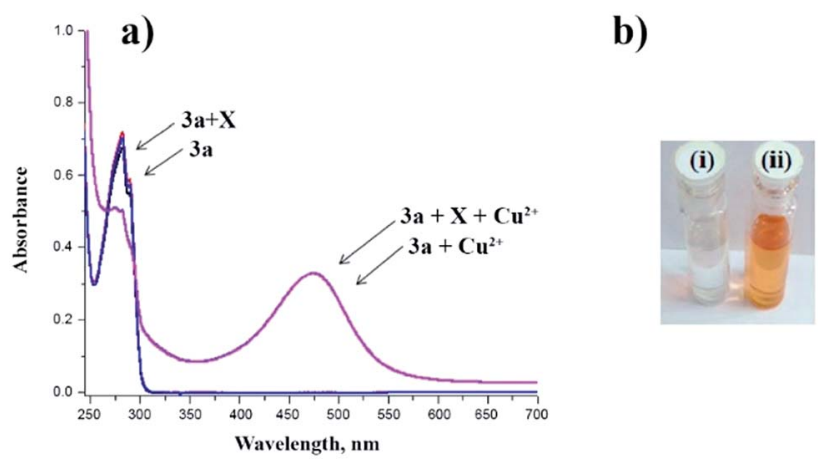

Fig. 1 (a) UV-Vis spectra of $3 a$ in the presence of $\mathrm{Cu}^{2+}$ and different metal cations (40 equivalent) in $\mathrm{CH}_{3} \mathrm{CN}$. (b) The color change of the solution, upon $\mathrm{Cu}^{2+}$ was added: (i) $3 a$ alone; (ii) $3 a+\mathrm{Cu}^{2+}$.

As most of tryptophan residues in Lys have polar-uncharged and hydrophobic amino acids in their vicinity, it is possible to establish hydrogen bonds and hydrophobic interactions toward compound $3 \mathbf{f}$ at the same time. One of the advantages of using compound $\mathbf{3 f}$ as a Lys inhibitor is that the formation of Lys : $\mathbf{3 f}$ complex cannot be considerably affected by the presence of biologically important metal ions. ${ }^{54}$

In the most recent work, one-pot 4-component reaction of compound 3 with 1,1-bis (methylthio)-2-nitroethylene, 1,2ethanediamine, and malononitrile was carried out in ethanol as solvent and in the presence of $10 \mathrm{~mol} \%$ piperidine as a basic

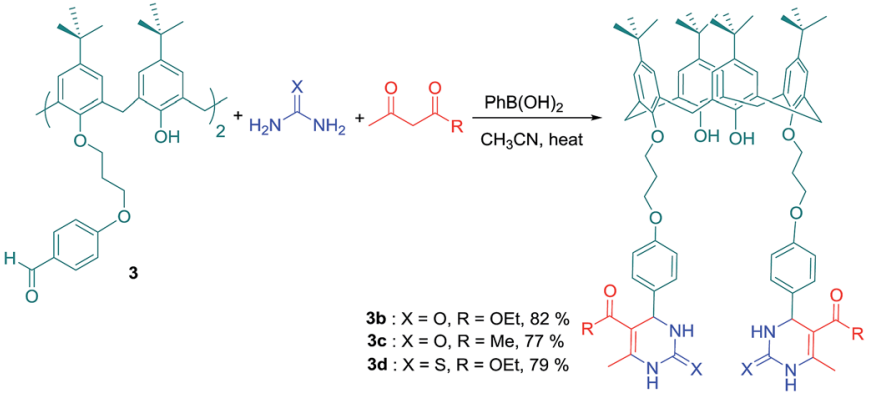

Scheme 4 Biginelli-3-component reaction of calixarene dialdehyde 3.

catalyst under reflux condition to afford the new multifunctional calix[4]arene $\mathbf{3 g}$ (Scheme 8).

The binding property of compound $\mathbf{3 g}$ with four selected proteins was investigated by fluorescence quenching titration. Among them, BLG showed the most dramatic decrease in the fluorescence intensity without any shift in the maximum emission wavelength (Fig. 3). These results imply a strong interaction between $\mathbf{3 g}$ and BLG without considerable conformational changes in the protein structure.

As shown in Table 3, the binding constant for $\mathbf{3 g}$ : BLG complex was found to be significantly higher than the binding constant for the three other proteins. ${ }^{55}$

Kabachnik-Fields reaction, a named 3-component reaction of an aldehyde/ketone with an amine and a di-/trialkyl phosphite, provides a useful procedure to yield $\alpha$-aminophosphonate derivatives. ${ }^{56,57}$ These valuable organophosphorus compounds have many intriguing biological activities. Actually, they are key substrates to obtain $\alpha$-aminophosphosphoric acids which are $\alpha$-amino acids analogues and can exhibit a broad range of biological activities. A series of novel calix[4]arene based $\alpha$-aminophosphonate derivatives were described by Stoikov and his coworkers through Kabachnik-Fields reaction. In this reaction the amino alkyl derivatives of $p$-tert-butylcalix[4] arene (compounds $\mathbf{4}$ and 5) were used as the platform to construct $\alpha$-aminophosphonate fragments at the lower rim of the calix[4]arene annulus (Scheme 9).

Previously, acyclic $\alpha$-aminophosphonates such as diethyl(2(octadecylamino)propan-2-yl)phosphonate a and diethyl((octadecylamino) (phenyl)methyl)phosphonate b were 
Scheme 5 Synthesis of hexaamide derivatives through 4-component reaction of compound 3 .

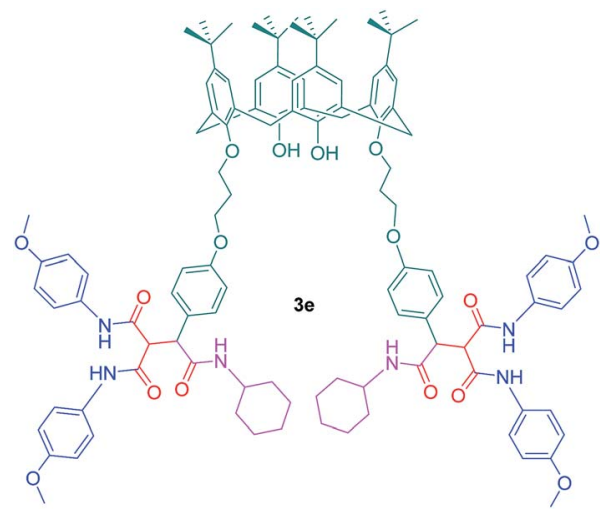

Scheme 6 Compound 3e as a BLG host.
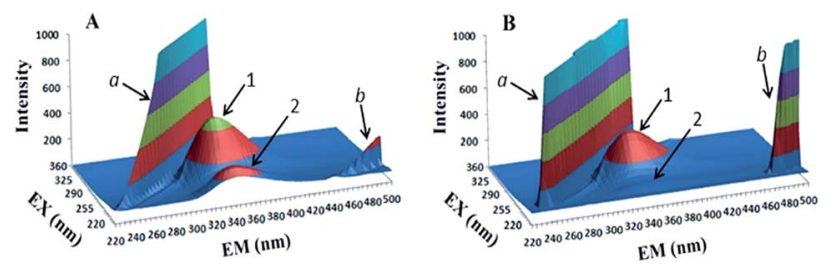

Fig. 2 Three-dimensional fluorescence spectra of BLG and 3e : BLG complex.

Table 1 Three-dimensional fluorescence spectral characteristics of BLG and 3e : BLG system

\begin{tabular}{llll}
\hline Systems & Peak & Peak position $\lambda_{\mathrm{ex}} / \lambda_{\mathrm{em}}\left[\mathrm{nm} \mathrm{nm}^{-1}\right]$ & Intensity \\
\hline BLG & 1 & $280 / 340$ & 589 \\
& 2 & $230 / 340$ & 271 \\
BLG : 3e $(1: 2)$ & 1 & $280 / 340$ & 327 \\
& 2 & $230 / 340$ & 95
\end{tabular}

successfully used as an efficient and selective carrier to transport some diacids and $\alpha$-hydroxy acids through a certain liquidimpregnated membrane (Scheme 10)..$^{58}$

But in this work, the use of $p$-tert-butylcalix[4]arene as a platform with three-dimensional structure could modify the selectivity through preorganization of binding sites.

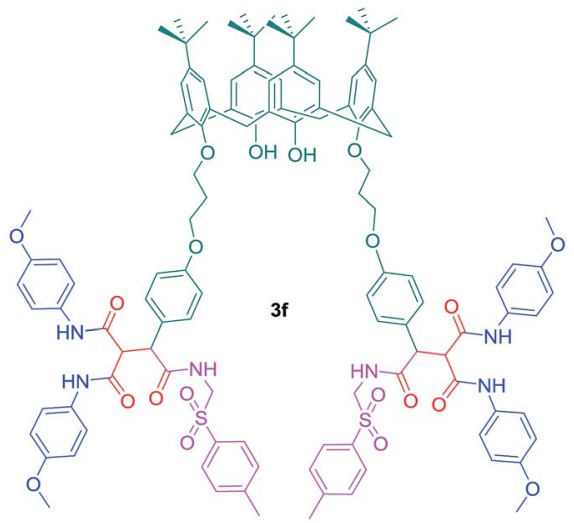

Scheme 7 Compound $3 f$ as an inhibitor for Lysozyme enzyme.

Table 2 Binding constants of proteins with compound $3 \mathrm{f}$

\begin{tabular}{lc}
\hline Proteins & $K_{\mathrm{A}}\left(\mathrm{M}^{-1}\right)$ \\
\hline Lys & $2.96 \times 10^{6}$ \\
BLG & $1.14 \times 10^{5}$ \\
BSA & $8.34 \times 10^{4}$ \\
HSA & $7.84 \times 10^{4}$
\end{tabular}

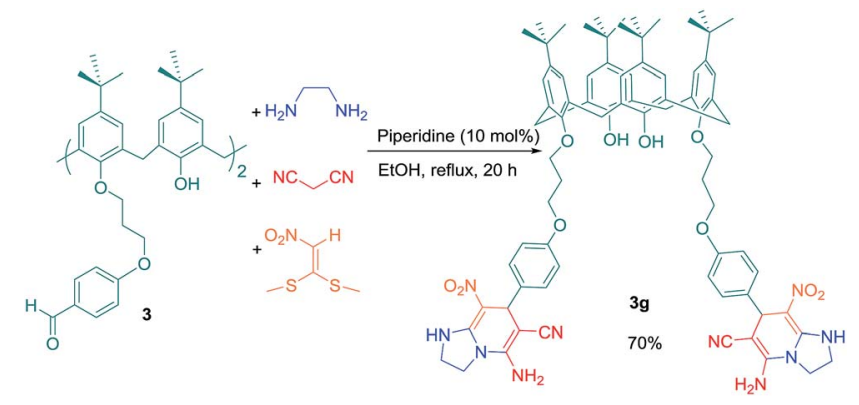

Scheme 8 Synthesis of multifunctional calix[4]arene $3 \mathrm{~g}$

The transport ability of compounds $\mathbf{4 a}$ and $\mathbf{5 a}$ for studied hydroxycarboxylic acids was considerably different from acyclic $\alpha$-aminophosphonates a and b (Fig. 4). This implies the higher degree of preorganization of functional substituents and the 


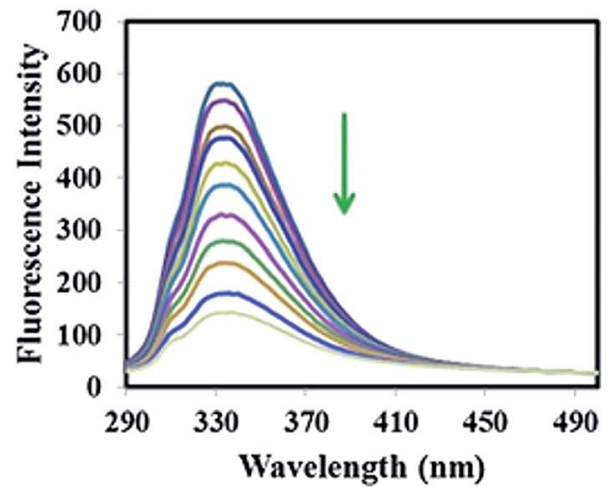

Fig. 3 Changes in fluorescence spectra of $B L G(1 \mu M)$ upon addition of compound $3 g(0-3.3 \mu \mathrm{M})$.

Table 3 Binding constants of proteins with compound $3 \mathrm{~g}$

\begin{tabular}{ll}
\hline Proteins & $K_{\mathrm{A}}\left(\mathrm{M}^{-1}\right)$ \\
\hline BLG & $1.06 \times 10^{6}$ \\
Lys & $2.66 \times 10^{5}$ \\
BSA & $9.04 \times 10^{4}$ \\
HSA & $5.22 \times 10^{4}$
\end{tabular}

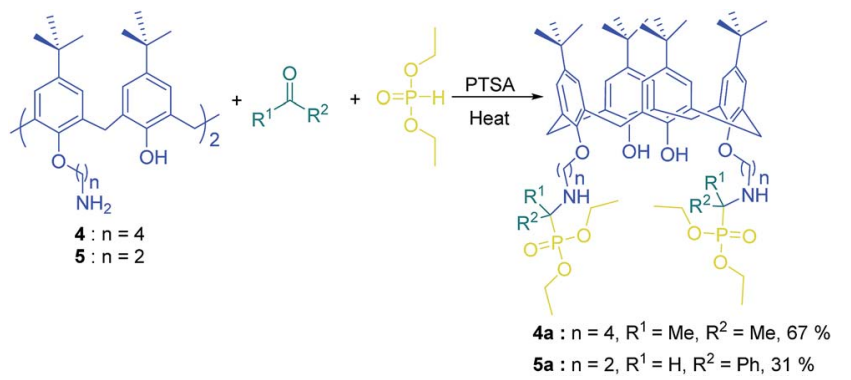

Scheme 9 Kabachnik-Fields-3-component reaction of calixarene diamine 4 and 5 .

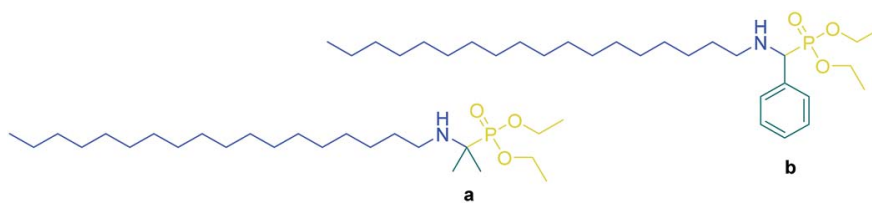

Scheme 10 Two acyclic $\alpha$-amino phosphonates $\mathrm{a}$ and $\mathrm{b}$ as transmembrane carriers for hydroxycarboxylic acids.

importance of structural and geometric correlations between the binding sites and substrates. ${ }^{59}$

In another study, novel lower rim $\alpha$-hydrazinotetrazolocalix [4]arene derivatives were achieved by Ugi-azide-4-component reaction of calixarene dihydrazide 6 with an aliphatic ketone compound, cyclohexyl or tert-butyl isocyanide, and trimethylsilyl azide (Scheme 11). The developed protocol is an operationally simple method to afford the desired products in good yields under mild conditions.
Furthermore, the metal cation binding properties of compound $\mathbf{6 a}$ as the model compound were investigated by fluorescence titration with cations as metal perchlorates (Scheme 12).

As shown in Fig. 5, fluorescence quenching study indicated that compound 6a toward $\mathrm{Ni}^{2+}$ had the highest association constant $\left(K_{\mathrm{a}}=1.70 \times 10^{7} \mathrm{M}^{-1}\right)$ to form a $\mathrm{Ni}: \mathbf{6 a}$ complex. Fluorescent sensors for $\mathrm{Ni}^{2+}$ detection are rare and in most of cases, they have serious interference problems from other heavy and transition metal ions. The compound $\mathbf{6 a}$ as a specific fluorescent sensor can form complex with $\mathrm{Ni}^{2+}$ even in the presence of other metal ions such as $\mathrm{Li}^{+}, \mathrm{Na}^{+}, \mathrm{K}^{+}, \mathrm{Ba}^{2+}, \mathrm{Mn}^{2+}$, $\mathrm{Co}^{2+}, \mathrm{Cu}^{2+}, \mathrm{Zn}^{2+}$, and $\mathrm{Hg}^{2+}$ at 1 equivalent (Fig. 6). ${ }^{11}$

\section{Upper rim functionalized calix[4]arene derivatives}

Upper rim functionalization is generally more complicated than lower rim. The first step is to remove tert-butyl groups from the upper rim that is carried out in good yields by the use of $\mathrm{AlCl}_{3}{ }^{60}$ Until now, an enormous amount of effort has been devoted by a large number of researchers to develop diverse functional groups at the upper rim, thereby a fairly extended library of upper rim substituted calixarenes have been available. ${ }^{61}$ Recently, some of upper rim functionalized calix[4]arenes have been used in several MCRs. As the first attempt Varma and coworkers utilized novel isocyanocalix[4]arene 7 and aminocalix [4]arene 8 separately in Ugi-4CR in order to achieve two sorts of calixarene based $\alpha$-acylaminocarboxamide derivatives (Schemes 13 and 14). This synthetic method provides a general and straightforward route to establish peptoide chains with heteroaromatic and chromophore substitutions on the upper rim. Unlike many other reported peptidocalixarenes, these compounds have excellent solubility in non-polar solvents. ${ }^{41}$

Calix[4]arene diamine 8 was also used by Deng et al. in a simple one-pot 4-CR. This reaction was carried out between one equivalent of compound $\mathbf{8}$ and two equivalent of an aldehyde, benzil, and ammonium acetate in refluxing acetic acid to construct two imidazole rings, which are directly linked to the upper rim (Scheme 15). ${ }^{62}$

Two similar upper rim aminocalix[4]arenes $\mathbf{9}$ and $\mathbf{1 0}$ were applied in a 3-component approach by Mirza-Aghayan et al. In order to synthesize three novel acridine-calix[4]arene derivatives 9a, 9b and 10a (Scheme 16). The reaction was conducted in the presence of $6 \%$ tungstophosphoric acid hydrate as an efficient heteropolyacid catalyst in boiling ethanol as solvent.

Acridine derivatives have remarkable ability to reversibly intercalate into the helical structure of DNA, so the interaction of acridine-functionalized calix[4]arene derivatives with calf thymus DNA (CT-DNA) was investigated via fluorescence titration experiments in aqueous solution. The obtained results showed compound $\mathbf{9 b}$ has a larger association constant $\left(K_{\mathrm{f}}=\right.$ $\left.2.18 \times 10^{7}\right)$ than compound $9 \mathrm{a}\left(K_{\mathrm{f}}=3.75 \times 10^{6}\right)$. Furthermore, association constant in compound 10a $\left(K_{\mathrm{f}}=6.36 \times 10^{7}\right)$ revealed that the increase of the number of acridine moieties could not considerably improve the affinity toward CT-DNA. ${ }^{63}$ 

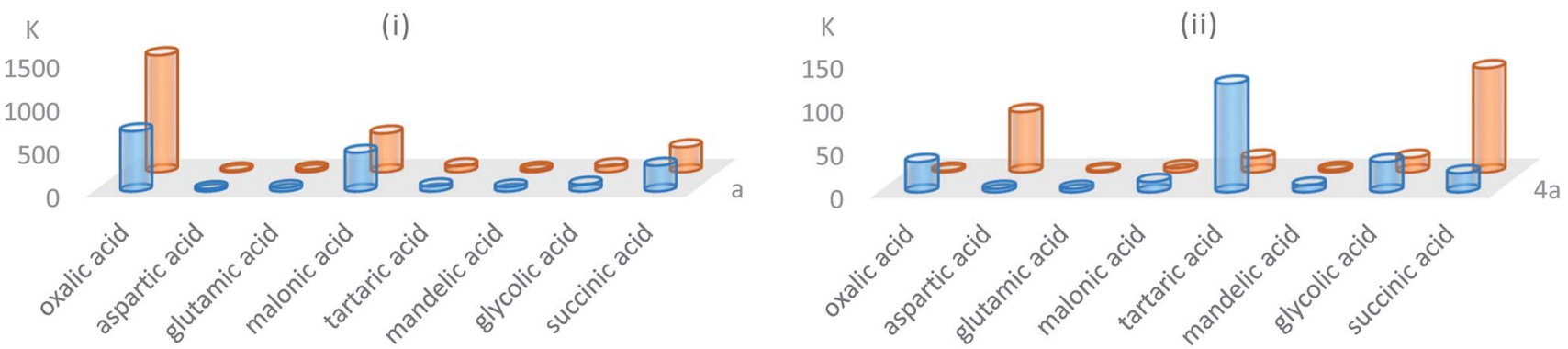

Fig. 4 Transport enhancement coefficients ( $K=$ transfer flux through a liquid-impregnated membrane with carrier/transfer flux through a liquidimpregnated membrane without carrier) for certain organic acids (i) carriers a, b and (ii) carriers $4 a, 5 a$.

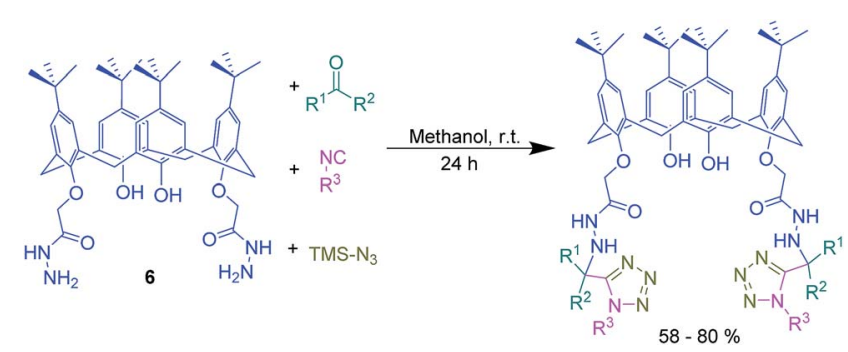

Scheme 11 Ugi-azide-4-component reaction of calixarene dihydrazide 6.

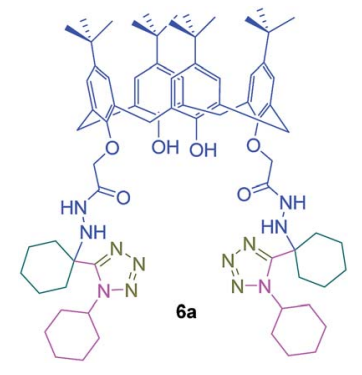

Scheme 12 Compound 6 a as a selective host for $\mathrm{Ni}^{2+}$ cation.

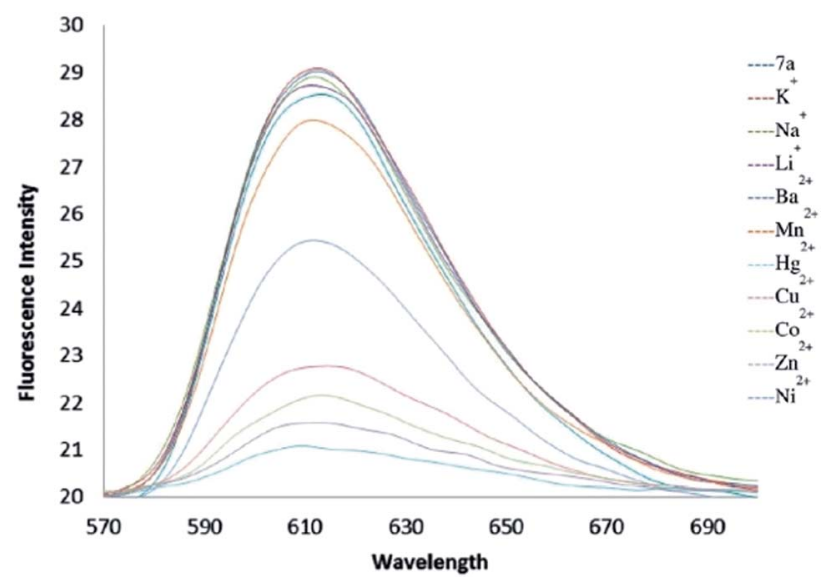

Fig. 5 Fluorescence intensity changes of compound $6 \mathrm{a}$ in $\mathrm{CH}_{3} \mathrm{CN}$ upon addition of 1 equivalent of various metal perchlorates.

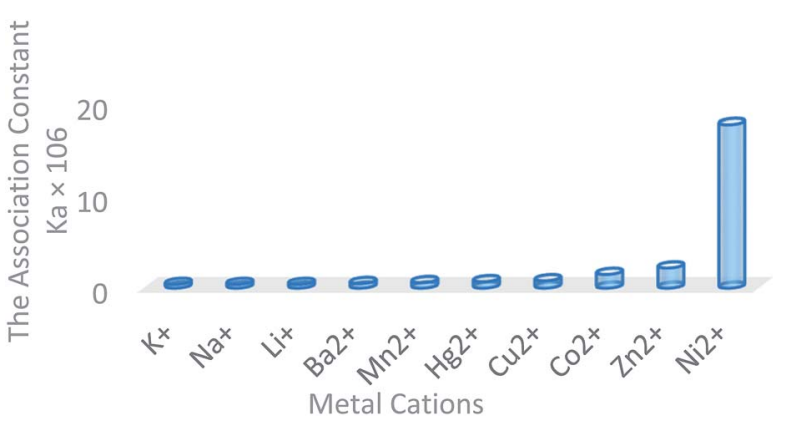

Fig. 6 The association constants of 6 a with metal cations (1: 1 binding model) in $\mathrm{CH}_{3} \mathrm{CN}$.

Along the same lines, a highly selective fluorescent chemosensor for $\mathrm{NADH}$ was described via a pseudo-five-component reaction of two equivalent of mono-aminocalix[4]arene 9 with 4-nitrobenzaldehyde, Meldrum's acid, and tert-butyl isocyanide in $\mathrm{CH}_{2} \mathrm{Cl}_{2}$ (Scheme 17).

This reaction led to formation of a dimeric structure of calix [4]arene. The product showed unique selectivity toward NADH to form a $1: 1$ stoichiometric complex and was able to detect at least $16.3 \mu \mathrm{g} \mathrm{\textrm {L } ^ { - 1 }} \mathrm{NADH}$ over various biomolecules with a binding constant of $3.74 \times 10^{5} \mathrm{M}^{-1}$. Actually, for compound 9c, the variation of the fluorescence intensity during complex formation with $\mathrm{NADH}$ in the presence of equal amounts of different biomolecules was almost constant. Additionally, the ${ }^{31} \mathrm{P}$ NMR spectra of NADH was significantly changed after formation of complex with compound 9c which indicated that $\mathrm{NADH}$ phosphate groups interact with the amide moieties of the chemosensor through hydrogen bonding (Fig. 7). ${ }^{16}$

Two new calix[4]arene based receptors 11a and 11b were introduced for saccharide recognition in aqueous solution by Mirza-Aghayan et al. For this purpose, the mono-aldehyde calix [4] arene $\mathbf{1 1}$ as a carbonyl compound was used in two different MCRs (Schemes 18 and 19). In the first one, novel 1,4dihydropyridine-calix[4]arene 11a was achieved through a pseudo 3-CR of compound $\mathbf{1 1}$ with two equivalent of methyl 3aminocrotonate in the presence of TMSCl. The interaction of 1,4-dihydropyridine-calix[4] arene 11a toward some mono-and disaccharides was investigated via fluorescence and ${ }^{1} \mathrm{H}$ NMR titration. The obtained results revealed that compound 11a has a 31-fold greater binding affinity for sorbitol $\left(2.35 \times 10^{5} \mathrm{M}^{-1}\right)$ 


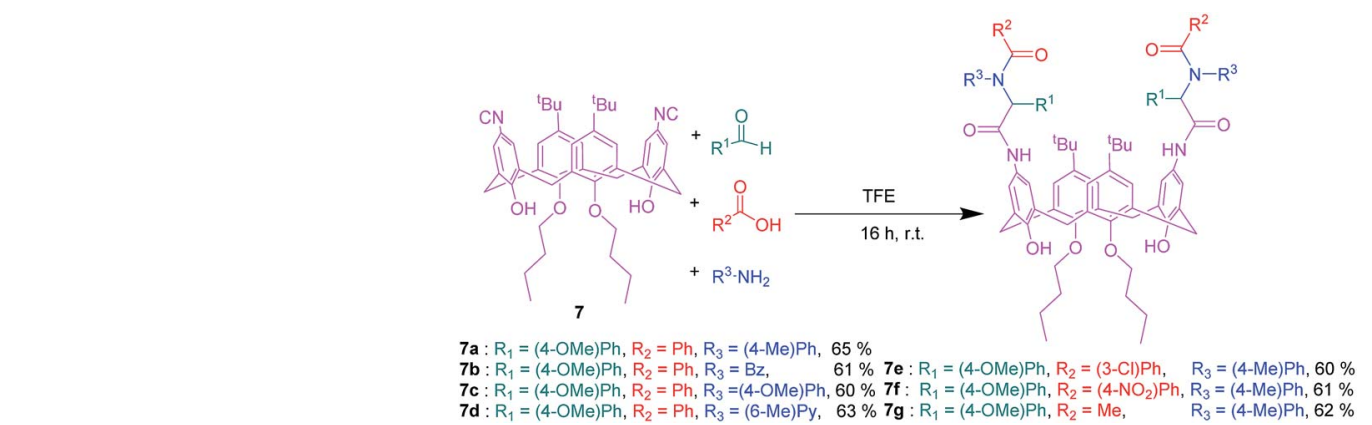

Scheme 13 Ugi-4-component reaction of isocyanocalix[4]arene 7.

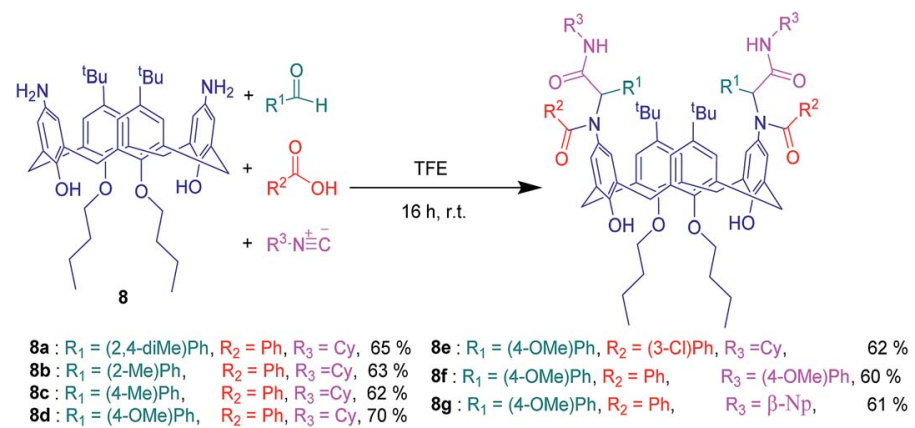

Scheme 14 Ugi-4-component reaction of aminocalix[4]arene 8

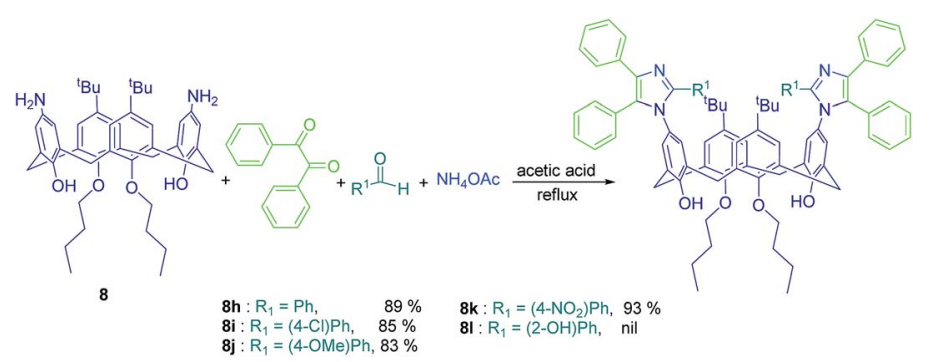

Scheme 15 Imidazole-calix[4]arene derivatives synthesis from 4-component reaction of compound 8 .

relative to mannitol $\left(7.50 \times 10^{3} \mathrm{M}^{-1}\right)$, but lone 1,4-dihydropyridine didn't show any selectivity between the two sugar alcohols. In continuation of this study, 2-amino-pyrimidine-calix[4]arene 11b was afforded through a 3-CR between the mono-aldehyde calix[4]arene 11, ethyl cyanoacetate, guanidinium carbonate and catalytic amount of $\mathrm{NH}_{2}-\mathrm{SBA}-15$. The product as

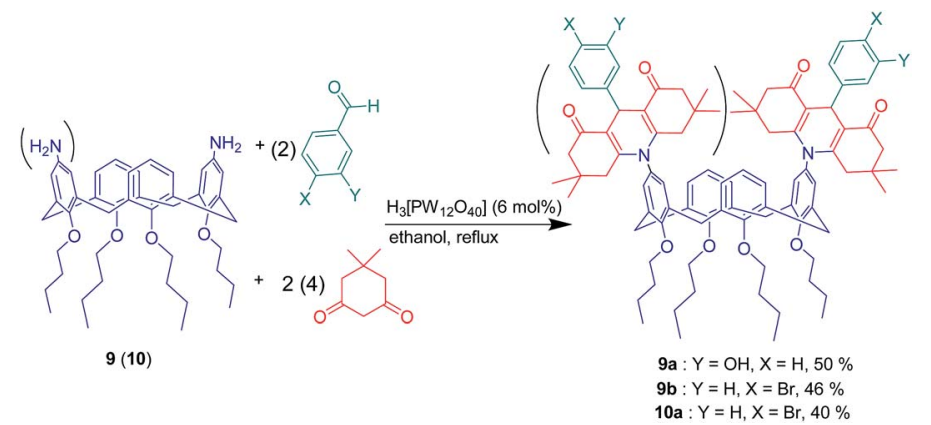

Scheme 16 Acridine-calix[4]arene derivatives synthesis from 3-component reaction of compound 9 (10). 


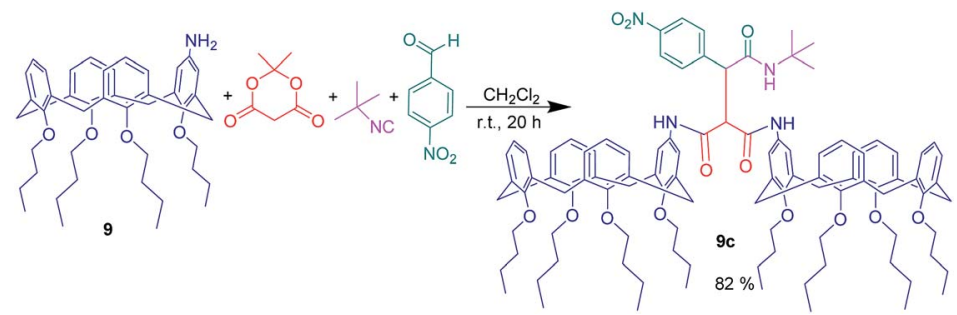

Scheme 17 Pseudo-five-component reaction of mono-aminocalix[4]arene 9.

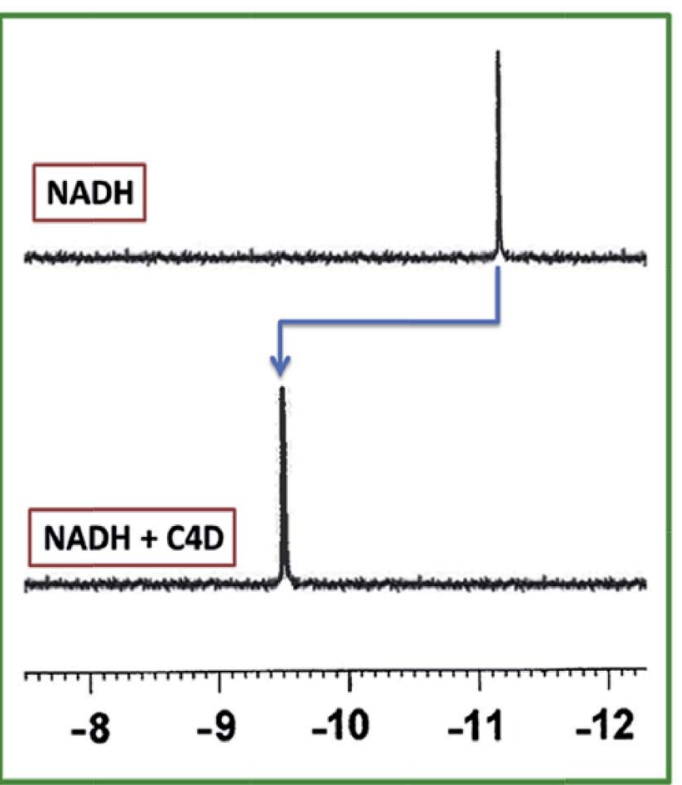

Fig. $7{ }^{31} \mathrm{P}$ NMR spectra of $\mathrm{NADH}$ and $\mathrm{NADH}$ with equivalent amount of $9 \mathrm{c}$ in $\mathrm{D}_{2} \mathrm{O}$.

a saccharide recognizer displayed highest binding affinity toward glucose $\left(3.13 \times 10^{5} \mathrm{M}^{-1}\right)$ and fructose $\left(3.60 \times 10^{5} \mathrm{M}^{-1}\right)$ over the other saccharides. ${ }^{64}$

Another use of upper-rim aldehyde substituted calix[4]arene was presented by Varma et al. (Scheme 20). In this work, a solution of dialdehyde 12, ethyl acetoacetate, and urea in acetonitrile was heated under reflux in the presence of catalytic amount (10 mol\%) phenylboronic acid to afford the

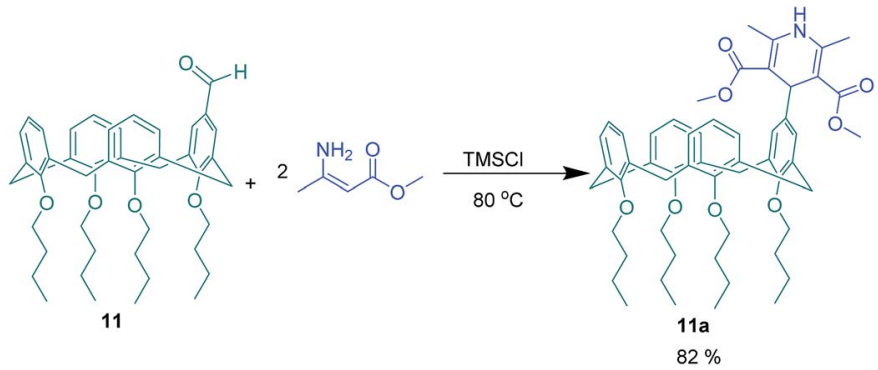

Scheme 18 1,4-Dihydropyridine-calix[4]arene synthesis from pseudo 3 -component reaction of compound 11 .

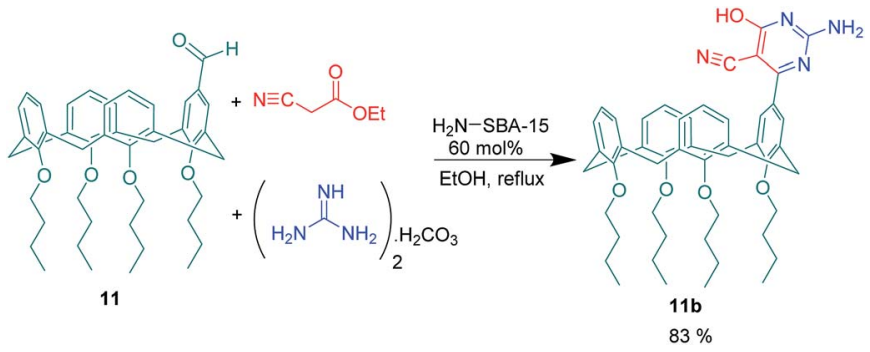

Scheme 19 2-Amino-pyrimidine-calix[4]arene synthesis from 3component reaction of compound 11 .

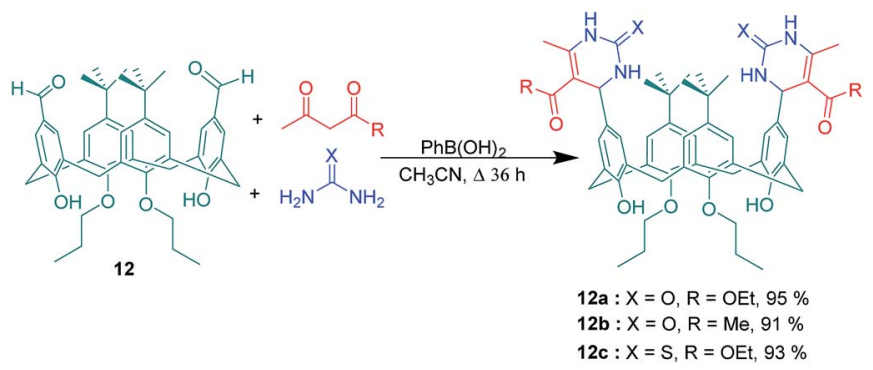

Scheme 20 Biginelli-3-component reaction of calixarene dialdehyde 12.

corresponding dihydropyrimidine derivative 12a in quantitative yield. One of the special features of this case is direct connection of aromatic nucleus to the stereo centres in two dihydro pyrimidine substituents. In addition, two further upper rim dihydropyrimidine substituted calix[4] arenes $\mathbf{1 2 b}$ and $\mathbf{1 2 c}$ were synthesized through replacement of ethyl acetoacetate by acetyl acetone and urea by thiourea. Although these three calix[4] arene derivatives showed no significant binding affinity toward investigated cations and anions, the study of the aggregation behaviour by ${ }^{1} \mathrm{H}$ NMR spectroscopy in $\mathrm{CDCl}_{3}$ revealed compound 12a tends to aggregate due to its intermolecular hydrogen bonds in solution. ${ }^{51}$

\section{Conclusion}

In conclusion, the examples highlighted in this review demonstrate that calix[4]arene derivatives can be successfully used to produce highly functionalized building blocks by MCRs in a convenient manner with a minimum of synthetic steps. As 
previously described, most of the products have outstanding properties in supramolecular chemistry which can be applied for chemical sensing purposes, such as recognition of small ions or even large biological macromolecules, like proteins and nucleic acids. Over the last decade, only four-membered ring calixarenes have been applied in MCRs, so there is potential to develop MCRs by other sizes of calixarene annulus. The diversity of the products obtained by multicomponent reactions in combination with multi-valency properties of calixarenes inspire chemists to develop various highly functionalized derivatives of calixarenes as new multivalent ligands. Additionally, the supramolecular properties of these new products, such as establishment of non-covalent interactions and selfcomplimentary may be useful to encapsulate certain kinds of drugs or genes to deliver them to specific tissues. It seems that in the coming decade there will be an increase in the number of multicomponent methods for functionalizing calixarene derivatives. Of course, it is expected the final product will be more specialized and more purposeful.

\section{Conflicts of interest}

There are no conflicts to declare.

\section{Acknowledgements}

This work was financially supported by Chemistry and Chemical Research Center of Iran. Zadmard is also very grateful to German Academic Exchange Service (DAAD) for granting a three-month research fellowship.

\section{References}

1 J. W. Steed and J. L. Atwood, Supramolecular chemistry, John Wiley \& Sons, 2013.

2 J.-M. Lehn, Chem. Soc. Rev., 2007, 36, 151-160.

3 K. Ariga and T. Kunitake, Supramolecular Chemistry Fundamentals and Applications: Advanced Textbook, Springer Berlin Heidelberg, 2006.

4 J.-M. Lehn, Science, 1985, 227, 849.

5 J. W. Steed, D. R. Turner and K. Wallace, Core concepts in supramolecular chemistry and nanochemistry, John Wiley \& Sons, 2007.

6 J.-M. Lehn, Science, 1993, 260, 1762-1764.

7 J.-M. Lehn, Chem. Soc. Rev., 2017, 46, 2378-2379.

8 H. M. Chawla, N. Pant, B. Srivastava and S. Upreti, Org. Lett., 2006, 8, 2237-2240.

9 J. Vicens and V. Böhmer, Calixarenes: A Versatile Class of Macrocyclic Compounds, Springer Netherlands, 2012.

10 C. D. Gutsche and R. S. o. C. I. Services, Calixarenes Revisited, Royal Society of Chemistry, 1998.

11 N. S. Alavijeh, R. Zadmard, S. Ramezanpour, S. Balalaie, M. S. Alavijeh and F. Rominger, New J. Chem., 2015, 39, 6578-6584.

12 D. Diamond and K. Nolan, Anal. Chem., 2001, 73, 22A-29A.

13 A. Ikeda and S. Shinkai, Chem. Rev., 1997, 97, 1713-1734.
14 B. S. Creaven, D. F. Donlon and J. McGinley, Coord. Chem. Rev., 2009, 253, 893-962.

15 M.-Z. Asfari, V. Böhmer, J. Harrowfield and J. Vicens, Calixarenes 2001, Springer Science \& Business Media, 2007.

16 R. Zadmard, P. Akbari-Moghaddam, S. Darvishi and M. Mirza-Aghayan, Tetrahedron, 2017, 73, 604-607.

17 N. S. Alavijeh, R. Zadmard, S. Balalaie, M. S. Alavijeh and N. Soltani, Org. Lett., 2016, 18, 4766-4769.

18 K. Sharma and P. Cragg, Chem. Sens., 2011, 1, 1-18.

19 R. V. Rodik, A. S. Klymchenko, Y. Mely and V. I. Kalchenko, J. Inclusion Phenom. Macrocyclic Chem., 2014, 80, 189-200.

20 A. de Fatima, S. A. Fernandes and A. A. Sabino, Curr. Drug Discovery Technol., 2009, 6, 151-170.

21 Y. Zhou, H. Li and Y.-W. Yang, Chin. Chem. Lett., 2015, 26, 825-828.

22 F. N. Pur, Mol. Diversity, 2016, 20, 781-787.

23 C. D. Gutsche and K. C. Nam, J. Am. Chem. Soc., 1988, 110, 6153-6162.

24 Z. Dong, Q. Luo and J. Liu, Chem. Soc. Rev., 2012, 41, 78907908.

25 S. Yaghoubnejad, K. T. Heydar, S. H. Ahmadi and R. Zadmard, Biomed. Chromatogr., 2018, 32, e4122.

26 B. Mokhtari, K. Pourabdollah and N. Dalali, Chromatographia, 2011, 73, 829-847.

27 M. Śliwka-Kaszyńska, Crit. Rev. Anal. Chem., 2007, 37, 211224.

28 B. Mokhtari, K. Pourabdollah and N. Dallali, J. Radioanal. Nucl. Chem., 2010, 287, 921-934.

29 N. Morohashi, S. Iijima, K. Akasaka and T. Hattori, New J. Chem., 2017, 41, 2231-2234.

30 M. G. Chini, S. Terracciano, R. Riccio, G. Bifulco, R. Ciao, C. Gaeta, F. Troisi and P. Neri, Org. Lett., 2010, 12, 53825385.

31 W. M. Nau, G. Ghale, A. Hennig, H. Bakirci and D. M. Bailey, J. Am. Chem. Soc., 2009, 131, 11558-11570.

32 A. I. Vovk, L. A. Kononets, V. Y. Tanchuk, S. O. Cherenok, A. B. Drapailo, V. I. Kalchenko and V. P. Kukhar, Bioorg. Med. Chem. Lett., 2010, 20, 483-487.

33 H. N. Genc and A. Sirit, J. Inclusion Phenom. Macrocyclic Chem., 2018, 90, 39-49.

34 S.-Y. Li, Y.-W. Xu, J.-M. Liu and C.-Y. Su, Int. J. Mol. Sci., 2011, 12, 429-455.

35 Y.-S. Zheng and J. Luo, J. Inclusion Phenom. Macrocyclic Chem., 2011, 71, 35.

36 Y. Huang, A. Yazbak and A. Dömling, in Green Techniques for Organic Synthesis and Medicinal Chemistry, John Wiley \& Sons, Ltd, Chichester, 2012.

37 S. K. Sharma, A. Mudhoo and W. Zhang, Green Chemistry for Environmental Sustainability, CRC Press, Boca Raton, 1st edn, 2010.

38 L. Reguera, Y. Méndez, A. R. Humpierre, O. Valdés and D. G. Rivera, Acc. Chem. Res., 2018, 51, 1475-1486.

39 E. Marqués-López and R. P. Herrera, Multicomponent Reactions: Concepts and Applications for Design and Synthesis, John Wiley \& Sons, Hoboken, New Jersey, 2015, pp. 382-415, DOI: 10.1002/9781118863992.ch1. 
40 R. Afshari and A. Shaabani, ACS Comb. Sci., 2018, 20, 499528.

41 A. Savithri, S. Thulasi and L. Varma, Tetrahedron, 2012, 68, 6323-6328.

42 A. Dömling, W. Wang and K. Wang, Chem. Rev., 2012, 112, 3083-3135.

43 Z. Li, H. Xing, G. Huang, X. Sun, J. Jiang and L. Wang, Sci. China: Chem., 2011, 54, 1726-1734.

44 T. R. M. Rezende, J. O. S. Varejão, A. L. L. d. A. Sousa, S. M. B. Castañeda and S. A. Fernandes, Org. Biomol. Chem., 2019, 17, 2913-2922.

45 P. Sarkar and C. Mukhopadhyay, Tetrahedron Lett., 2016, 57, 4306-4310.

46 L. Baldini, A. Casnati, F. Sansone and R. Ungaro, Chem. Soc. Rev., 2007, 36, 254-266.

47 A. Arduini, M. Fabbi, M. Mantovani, L. Mirone, A. Pochini, A. Secchi and R. Ungaro, J. Org. Chem., 1995, 60, 1454-1457.

48 H. M. Chawla, S. N. Sahu and R. Shrivastava, Tetrahedron Lett., 2007, 48, 6054-6058.

49 A. Savithri, S. Thulasi and R. L. Varma, J. Org. Chem., 2014, 79, 1683-1689.

50 G. C. Tron, A. Minassi and G. Appendino, Eur. J. Org. Chem., 2011, 2011, 5541-5550.

51 A. Savithri, C. N. Chinnan and L. Varma, Tetrahedron, 2015, 71, 9667-9672.

52 S. Khatun, J. Chem. Thermodyn., 2018, 126, 43-53.

53 R. Zadmard, P. Akbari-Moghaddam, S. Darvishi and M. Mirza-Aghayan, Eur. J. Org. Chem., 2016, 2016, 3894-3899.

54 R. Zadmard, S. Darvishi and P. Akbari-Moghaddam, J. Inclusion Phenom. Macrocyclic Chem., 2016, 86, 27-32.
55 M. Esmaielzade Rostami, B. Gorji and R. Zadmard, J. Heterocycl. Chem., 2018, 55, 2532-2537.

56 S. Bhagat and A. K. Chakraborti, J. Org. Chem., 2007, 72, 1263-1270.

57 V. H. Tillu, D. K. Dumbre, R. D. Wakharkar and V. R. Choudhary, Tetrahedron Lett., 2011, 52, 863-866.

58 I. I. Stoikov, N. A. Fitseva, L. R. Akhmetzyanova, L. I. Gafioullina, I. S. Antipin, V. F. Zheltukhin, A. I. Devyaterikova, V. A. Al"fonsov and A. I. Konovalov, Russ. Chem. Bull., 2004, 53, 1577-1583.

59 M. N. Agafonova, O. A. Mostovaya, I. S. Antipin, A. I. Konovalov and I. I. Stoikov, Mendeleev Commun., 2012, 22, 80-82.

60 D. Gutsche, in Calixarenes in the Nanoworld, ed. J. Vicens, J. Harrowfield and L. Baklouti, Springer Netherlands, Dordrecht, 2007, pp. 1-19, DOI: 10.1007/978-1-4020-50224 1.

61 C. D. Gutsche, in Calixarenes: A Versatile Class of Macrocyclic Compounds, ed. J. Vicens and V. Böhmer, Springer Netherlands, Dordrecht, 1991, pp. 3-37, DOI: 10.1007/97894-009-2013-2_1.

62 B. Zhao, Y.-Y. Ruan and M.-j. Ma, Heterocycles, 2013, 87, 1917-1924.

63 M. Mirza-Aghayan, M. Yarmohammadi, R. Zadmard and R. Boukherroub, Supramol. Chem., 2014, 26, 442-449.

64 M. Mirza-Aghayan, M. Yarmohammadi, N. Mohammadian, R. Zadmard and F. Asadi, J. Inclusion Phenom. Macrocyclic Chem., 2015, 83, 53-61. 